\title{
ESCRITA, PRÁTICAS DE LEITURA E CIRCULAÇÃO DE MANUAIS DE DEVOÇÃO ENTRE PORTUGAL E BRASIL NOS SECULOS XVIII E XIX
}

\author{
ELIANE CRISTINA DECKMANN FLECK \\ Universidade do Vale do Rio dos Sinos (UNISINOS)
}

MAURO DILLMANN

Universidade Federal do Rio Grande (FURG)

\section{RESUMO}

Os séculos XVIII e XIX se caracterizaram por uma significativa produção, edição e circulação de livros piedosos entre Portugal e a América portuguesa. Neste artigo, divulgamos um levantamento dos manuais que tiveram reedições ao longo deste período e que integram acervos brasileiros e portugueses, apontando para as possibilidades de sua análise a partir dos pressupostos teóricometodológicos das práticas de escrita e de leitura. Dentre os manuais reeditados que circularam nos dois lados do Atlântico estão Gritos das Almas do Purgatório, escrito pelo padre Joseph Boneta, Desengano dos Pecadores, de autoria do padre Alexandre Perier, e Mestre da Vida que ensina a viver e morrer santamente, do padre João Franco, sobre os quais nos detemos com maior profundidade, a fim de evidenciar sua larga utilização por clérigos e fieis católicos portugueses e brasileiros.

PALAVRAS-CHAVE: manuais de devoção; produção; circulação; leitura.

\section{ABSTRACT}

The 18th and 19th centuries were characterized by a significant production, edition and circulation of pious books between Portugal and Portuguese America. This article discloses a survey of the manuals that had re-editions throughout this period and that integrate Brazilian and Portuguese collections, pointing out the possibilities to their analysis through the theoretical and methodological principles of writing and reading practices. Among the re-edited manuals which circulated on both sides of the Atlantic are Gritos das Almas do Purgatório, written by priest Joseph Boneta, Desengano dos Pecadores, by priest Alexandre Perier and Mestre da Vida which teaches how to live and die saintly, by priest João Franco, on which there is a deeper focus, in order to evidence its broad utilization by Portuguese and Brazilian clergymen and Catholic believers.

KEYWORDS: devotion manuals; production; circulation; reading. 



\section{Introdução}

No período moderno, o domínio da cultura escrita era bastante limitado tanto na Península Ibérica, quanto na América Portuguesa. $O$ início do século XVIII, no entanto, assistiu à difusão da escrita e da imprensa, especialmente na Europa, que muito favoreceu a divulgação das ideias iluministas ${ }^{1}$. Em Portugal, apesar da limitação das práticas de leitura, textos escritos por filósofos, médicos, professores e religiosos eram divulgados por editores que se firmavam cada vez mais em Lisboa $^{2}$. Escritas, em sua maioria, com a finalidade de orientar moral e civilmente a sociedade, estas obras tiveram ampla circulação entre uma parcela da população alfabetizada ${ }^{3}$.

Neste artigo, nos detemos, especificamente, na significativa produção, edição e circulação de livros piedosos entre Portugal e o Brasil nos séculos XVIII e XIX e refletimos sobre suas possibilidades de leitura face à importância que assumiam como meios de orientação das condutas morais e devocionais dos fieis católicos. Para tanto, dividimos o texto da seguinte maneira: inicialmente, tecemos algumas considerações sobre essa literatura religiosa, sua produção na Europa católica pós-Trento e apontamos para evidências de sua circulação, principalmente a partir de um levantamento por nós realizado de alguns manuais de devoção que se encontram concomitantemente em arquivos brasileiros e portugueses; em seguida, mais detidamente, tecemos algumas considerações sobre três manuais, a saber: Gritos das Almas do Purgatório, Desengano dos Pecadores e Mestre da vida que ensina a viver e morrer santamente. Tais considerações versam sobre a aprovação, a escrita ou tradução, o desempenho editorial, a publicação, os acervos que contêm tais documentos, algumas considerações sobre os autores, alguns indícios de

\footnotetext{
${ }^{1}$ O século XVIII foi o século da expansão dos escritos de religião, filosofia, teatro, romances, política, ciências naturais, história, medicina, contos, cartas e relatos, que passaram a ocupar espaço privilegiado nas livrarias e bibliotecas europeias. CHARTIER, Roger. Do palco à página: publicar teatro e ler romances na época moderna, séculos XVI-XVIII. Rio de Janeiro: Casa da Palavra, 2002a, p. 98.

${ }^{2}$ Sobre livreiros de Lisboa, ver NEVES, Lúcia Maria Basto das. João Roberto Bourgeois e Paulo Martin: livreiros franceses no Rio de Janeiro, no início do Oitocentos. In: X Encontro Regional de História - Anpuh-RJ, História e Biografias, 2002, Rio de Janeiro. Anais Eletrônicos do X Encontro regional de História - História e Biografias. Rio de Janeiro: UERJ, 2002, p. 03; ARAÚJO, Ana Cristina. A morte em Lisboa: atitudes e representações, 1700-1830. Lisboa: Editorial Notícias, 1997, p. 143.

${ }^{3}$ ARAÚJO, Op. Cit., p. 145 . Os ambientes favoráveis à circulação de ideias, em Portugal do século XVIII, eram os salões, saraus, cafés, tabernas, por onde circulavam poetas, literatos e vasta clientela letrada. LOUSADA, Maria Alexandre. A rua, a taberna e o salão: elementos para uma geografia histórica das sociabilidades lisboetas nos finais do Antigo Regime. In: VENTURA, Maria da Graça A. Mateus. Os espaços de sociabilidade na Ibero-América (sécs. XVI-XIX). Lisboa: Colibri, 2004, p. 95-120. De modo geral, segundo Chartier, a Europa do século XVIII conheceu uma "revolução da leitura", com o crescimento da produção do livro, o sucesso dos pequenos formatos e a diminuição do preço dos livros graças à multiplicação das sociedades de leitura e à "ânsia de leitura". CHARTIER, Roger. Do códice ao monitor: a trajetória do escrito, Estudos Avançados, 8 (21), p. 185-199, 1994, p. 189.
} 
Escrita, práticas de leitura e circulação de manuais de devoção entre Portugal e Brasil nos séculos XVIII e XIX recepção e, ainda, sobre a estrutura das obras, como capítulos, temas abordados, sumário, aprovação e apresentação. Por último, realizamos algumas reflexões teóricas sobre práticas de leitura no Setecentos, relacionando-as à circulação evidenciada desta literatura religiosa.

\section{Os manuais de devoção: notas sobre a produção e circulação de um gênero literário}

Em relação aos livros religiosos, a palavra escrita e, muitas vezes, as imagens que eles continham, auxiliaram significativamente a Igreja Católica 4 em seu esforço, sobretudo no período pós-tridentino, de divulgação de devoções, de modos de expressar a fé, de comportamentos religiosos ideais, de maneiras de sentir, de práticas de confissão e de penitência. Tais escritos de moral e doutrina cristã configuravam o que denominamos aqui como "manuais de devoção".

Essas obras abordavam variados temas da vida e da expressão dos sentimentos religiosos dos católicos. Nelas, se enquadram os manuais de bem morrer, os manuais marianos e a "produção ascética e penitencial da Contrarreforma", que apresentam distinções pouco precisas entre si ${ }^{5}$. Apesar dessa imprecisão, optamos por classificá-los em manuais dedicados à instrução de devoção (à Virgem, a Jesus, à Igreja, aos santos), à orientação quanto aos modos de bem viver (virtudes cristãs), de pensamento e preparação para a morte e os que foram escritos para instruir o fiel sobre o estado da alma na sua imortalidade (Paraíso, Purgatório e Inferno).

Tais manuais eram divulgados em nome da fé católica, acompanhavam os padres em suas missas e sermões, os confessores em seus confessionários, os clérigos regulares em suas meditações e os leigos em sua vida cotidiana, na medida em que muitas destas obras propunham-se a ser "livrinhos" de ensinamentos diários ${ }^{6}$.

\footnotetext{
${ }^{4}$ Sermões, catecismos, missais, compêndios, breviários, obras edificantes circularam de forma restrita e sob a forma manuscrita durante a Idade Média. No período moderno, a impressão destes manuais favoreceu sua difusão entre um público letrado, garantindo, assim, a introdução de novas formas de sociabilidade familiar e pública. Veja-se JULIA, Dominique. Leituras e Contra-Reforma. In: CHARTIER, Roger; CAVALLO, Guglielmo. História da leitura no mundo ocidental. São Paulo: Ática, p. 79-116, 1999, p. 66; CHARTIER, Roger. $A$ ordem dos livros. Brasília: Ed.UnB, 1994, p.98. FLECK, Eliane Cristina Deckmann; DILLMANN, Mauro. Os sete pecados capitais e os processos de culpabilização em manuais de devoção do século XVIII, Topoi, Revista de História, Rio de Janeiro, v. 14, n. 27, p. 285-317, jul./dez. 2013.

${ }^{5}$ ARAÚJO, Op.Cit., p. 148.

${ }^{6}$ Biblioteca Joanina, Universidade de Coimbra. FRANCO, João. Terceiro Instruído na virtude, que professa a Veneravel Ordem da Milicia de Jesus Christo, e penitência de S. Domingo, em primeiro lugar, se expõem as notícias de todos os três estados, que esta Veneravel Ordem teve até agora no mundo: e em segundo lugar se ensina a vida Espiritual, e virtuosa, que deve fazer qualquer católico, que deveras deseja salva a sua alma. Composto pelo padre Fr. João Franco, religioso da ordem dos Pregadores, presentado em Theologia, consultor do Santo Ofício, e comissário da mesma Venerável Ordem Terceira. Lisboa: Oficina dos heredeiros de Antônio Pedroso Galram, 1742, p. 322.
} 
Entre estes ensinamentos - todos vinculados ao conhecimento pleno da doutrina cristã - estavam as instruções sobre os modos de devotar a Deus, a Jesus Cristo, aos santos e às inúmeras representações da Virgem Maria, que se traduziam em exemplos de orações, de exercícios de caridade e de comportamento moral dos fiéis em diversas ocasiões do cotidiano. Muitos destes manuais eram utilizados para reflexões religiosas diárias, que podiam ser realizadas antes ou após as orações, antes da confissão ou quando o fiel se sentisse tentado por influências demoníacas.

Estes manuais eram, geralmente, publicados sob a forma de livreto de mão - conhecidos, atualmente, como livros de bolso -, formato que favorecia tanto a prática da leitura individual ${ }^{7}$ e o "manuseio e transporte pelo devoto que seguia as orientações que nele constavam", quanto a aquisição, devido ao menor preço ${ }^{8}$. Este formato favorecia também as leituras coletivas, realizadas durante reuniões familiares ou lições catequéticas, que facilitavam a apropriação de seus discursos pelos ouvintes ${ }^{9}$. Desse modo, ensinamentos sobre condutas a serem observadas para a salvação das almas, modos de viver santamente e maneiras de bem morrer atingiam com sucesso os fiéis portugueses e espanhóis, tanto pela audição, quanto pela leitura ou visualização de imagens/gravuras.

Esse sucesso pode ser observado no grande número de edições que vários manuais de devoção dos séculos XVII e XVIII receberam, ${ }^{10}$ sendo que alguns deles chegaram a ser reeditados no século XIX ou mesmo no século XX. Muitos desses manuais receberam inúmeras reimpressões ao longo de mais de um século, o que parece indicar sua aceitação entre os leitores católicos e o reconhecimento de sua importância pela Igreja Católica. Cabe lembrar que somente após ganharem licenças do Santo Ofício, que se faziam acompanhar de pareceres favoráveis e elogiosos que recomendavam sua leitura, estas obras recebiam autorização para serem publicadas e divulgadas.

Tanto as campanhas de conversão, quanto a difusão desta literatura religiosa ao longo do século XVII visavam à observância de condutas morais e

7 GILMONT, Jean-François. Reformas protestantes e leitura. In: CAVALLO, Guglielmo. CHARTIER, Roger (org.). História da leitura no mundo Ocidental. São Paulo: Ática, 1999, p. 59.

8 FLECK, Eliane Cristina Deckmann; DILLMANN, Mauro. "A Vossa graça nos nossos sentimentos": a devoção à Virgem como garantia da salvação das almas em um manual de devoção do século XVIII. Revista Brasileira de História, v.32, n.63, p.83-118, jan.-jun. 2012, p. 84.

${ }^{9}$ FLECK e DILLMANN, Op. Cit., 2012, p. 84.

${ }^{10}$ Entre tantos outros, está o manual Mestre da Vida que ensina a viver e morrer santamente, do dominicano português João Franco, publicado inicialmente 1731 com reedições até 1882. Sobre esta obra, ver mais em: FLECK e DILLMANN, Op.Cit., 2012, 2013. Outras referências sobre este autor e sua obra também podem ser conferidas em: LOUREIRO, Olímpia Maria da Cunha. Uma leitura de sucesso no século XVIII: Mestre da vida que ensina a viver e morrer santamente. Revista Poligrafia, 3: 33-40, 1994; ARAÚJO, Op.Cit.; RODRIGUES, Cláudia. Nas fronteiras do Além. A secularização da morte no Rio de Janeiro, séculos XVIII e XIX. Rio de Janeiro: Arquivo Nacional, 2005, p. 63; RIBEIRO; SANTOS, Op.Cit.; RODRIGUES, Cláudia e DILLMANN, Mauro. "Desejando pôr a minha alma no caminho da salvação": modelos católicos de testamentos no século XVIII, História Unisinos, 17 (1): 1-11, jan/abr 2013. 

religiosas que observassem as leis de Deus ${ }^{11}$. Nelas, encontraremos relacionados diferentes modos de viver santamente, todos eles associados a personagens cujas vidas haviam sido marcadas pela humildade, caridade e pobreza. Além das referências à Bíblia, muitos autores de manuais recorriam aos doutores da Igreja, como Santo Agostinho e São Tomás de Aquino, e, também, aos filósofos clássicos grecorromanos, de modo a reforçar e incentivar a piedade nos fiéis leitores/ouvintes ${ }^{12}$.

Sabe-se que na França, entre 1650 e 1730 - período da "maré alta da Reforma Católica" -, a Igreja incentivou a "bagagem livresca" que os "bons" padres deveriam possuir. Além da Bíblia e dos catecismos, eles deveriam ter consigo comentários da Sagrada Escritura, livros de teologia moral e leituras espirituais. Tratava-se, como bem observado por Dominique Julia, do "esforço pedagógico da Contrarreforma", que pretendia fazer "dos membros do clero paroquial homens de estudo e de livros" ${ }^{13}$. No livro Buquê da missão (1700), escrito pelo escolástico Jean Leuduger, encontramos uma lista de "bons livros", dentre os quais estavam obras de Barry, Francisco de Sales, Luís de Granada, Alfonso Rodrigues e Lorenzo Scupoli.

Na França, esse tipo de literatura já vinha sendo, desde o século XVII, editada e publicada, com regularidade, por livreiros que eram, eles próprios, "com frequência intimamente ligados a uma ordem ou a uma congregação, um seminário, uma corrente espiritual"14. Também em Portugal e na Espanha, desde o século XVI, os manuais eram, geralmente, escritos por jesuítas, dominicanos, franciscanos e oratorianos, que percebiam "o sacerdote [como] o representante do saber, (...) do pensamento teológico-especulativo e da teologia moral, da exegese bíblica e da catequese doutrinária, o que se refletia no conjunto da produção impressa" ${ }^{\prime 15}$.

Portanto, ao longo dos séculos seguintes, os manuais de devoção, que, originariamente, estavam destinados ao clero e aos leigos, foram ganhando, cada vez mais, divulgação e alcance social. Todos eles, em geral, associavam a liturgia católica à dramatização do destino do homem no além, neste esforço

11 FLECK, Eliane Cristina Deckmann. Almas em busca de salvação: sensibilidade barroca no discurso jesuítico (século XVII). Revista Brasileira de História, v. 24, n. 48, São Paulo, p. 255300, 2004.

12 Para a análise de uma única publicação religiosa ver MORUJÃO, Isabel. Literatura devota em Portugal no tempo dos Filipes: o Memorial da Infância de Cristo de Soror Maria de Mesquita Pimentel, Via Spiritus, n.5, p. 177-208, 1998; OLIVEIRA, Maria Gabriela. Almas do Purgatório: meditação, devoção, convertio cordis. A propósito de alguns sermões de Pe. Inácio Martins S.J. In: ATAS DO COLÓQUIO INTERNACIONAL - A Companhia de Jesus na Península Ibérica nos sécs. XVI e XVII. Instituto de Cultura Portuguesa da Faculdade de Letras da Universidade do Porto, Portugal, p. 611-626, 2004; LOUREIRO, Op. Cit. E para a análise de várias obras religiosas que circularam em Portugal, ver MARQUES, Op. Cit., p. 300 e ARAÚJO, Op. Cit. Um levantamento da literatura religiosa presente na clausura feminina do século XVIII português foi realizado em MORUJÃO, Isabel. Livros e leituras na clausura feminina de setecentos, Revista da Faculdade de Letras, Línguas e Literaturas, Porto, XIX, p. 111-170, 2002.

13 JULIA, Op.Cit., 1999, p. 92.

14 JULIA, Op.Cit., 1999, p. 93, 108.

15 MARQUES, João Francisco. O livro religioso, em particular do âmbito da parenética e hagiologia, nos impressos, Revista da Faculdade de Letras, História, Porto, III série, v. 11, p. 293-303, 2010. Este historiador analisou os livros religiosos publicados por tipografias portuguesas do século XVI, chamando a atenção para os "tesouros bibliográficos da história cultural portuguesa". 
pedagógico de introspecção e de apropriação da teologia moral católica, ${ }^{16} \mathrm{com}$ a intenção de orientar e conduzir os leitores católicos em suas vidas cotidianas $^{17}$. Estratégia que pode ser observada no incentivo à memorização de rezas, ladainhas, cânticos e passagens bíblicas ${ }^{18}$.

Para a historiadora portuguesa Ana Cristina Araújo, que estudou inúmeros manuais de preparação para a morte, esta literatura, que "alimenta[va] a reflexão dos homens de Deus", ${ }^{19}$ reforçava, especialmente, a necessidade do arrependimento dos pecados, atitude tida como fundamental para uma conduta que observava os "mistérios da religião"20.

Este enquadramento dos religiosos e dos fiéis estava diretamente relacionado com os meios considerados eficazes para despertá-los à vida devota, dentre os quais estava o pensamento na morte, as visitas aos cemitérios e aos túmulos, as considerações sobre a imortalidade da alma ${ }^{21}$ e os alertas sobre os possíveis sofrimentos eternos das almas pecadoras.

Publicados em Portugal e na Espanha, nos séculos XVII e XVIII, estes manuais atravessaram o Atlântico, o que se pode constatar nas evidências de "aquisições de manuscritos e impressos feitas pelo clero secular e pelas ordens religiosas, que mantinham essas obras em suas bibliotecas" ${ }^{\prime 22}$. Mas o ingresso destes livros devocionais também se dava através do comércio de livros entre a Europa e o Brasil. Ao final do século XVII, a aquisição de livros era mediada por negociantes particulares, que, muitas vezes, atendiam às encomendas feitas por leigos católicos ${ }^{23}$.

Evidências do comércio e circulação desses manuais devocionais são os exemplares de suas várias edições, que podem ser encontrados tanto nos acervos de bibliotecas do Rio de Janeiro [Biblioteca Nacional] e do Rio Grande

${ }^{16}$ ARAÚJO, Op. Cit., p. 146.

${ }^{17}$ FLECK e DILLMANN, Op. Cit., 2012, 2013.

${ }^{18}$ ARAÚJO, Op.Cit., p. 145.

19 JULIA, Op.Cit., 1999, p. 96.

${ }^{20}$ ARAÚJO, Op.Cit., p. 147-148.

${ }^{21}$ ARAÚJO, Op.Cit., p. 147.

${ }^{22}$ Ibid. Muitas destas obras integravam acervos de bibliotecas de ordens religiosas, como o da chamada Livraria da Fazenda jesuítica de Santa Cruz, no Rio de Janeiro, conforme pode ser conferido no levantamento realizado por Marília Azambuja e Luísa Santos. RIBEIRO, Marília de Azambuja; SANTOS, Luísa. A Livraria da Fazenda Santa Cruz. In: AMANTINO, Márcia; ENGEMANN, Carlos (orgs.). Santa Cruz: de legado dos jesuítas à perola da Coroa. Rio de Janeiro: EdUERJ, 2013. Essa circulação de obras religiosas na América Portuguesa, inclusive em bibliotecas particulares, foi apontado por Luiz Villalta. De acordo com ele, o historiador Alcântara Machado, debruçado em 450 inventários de São Paulo, verificou que, no século XVII, dos 15 inventários que continham livros, somavam-se, ao todo, 55 títulos, a sua maior parte eram "obras devocionais" como Horas de rezar em linguagem, Floro Cristiano e Imagem da vida cristã. VILLALTA, Luiz. Bibliotecas privadas e práticas de leitura no Brasil Colonial, 1998. Disponível em http://www.caminhosdoromance.iel.unicamp.br/estudos/ensaios/bibliotecasbr.pdf. Acessado em 12/10/2011.

${ }^{23}$ Dentre os muitos exemplos, a historiadora Lúcia Neves destaca o caso do português João Roberto Bourgeois, que chegou ao Rio de Janeiro, em 1782, e se tornou um dos maiores editores já no início do século seguinte. Isto pode ser constatado nos jornais da cidade, nos quais Bourgeois noticiava as "obras novas" disponíveis em sua loja. NEVES, Op.Cit., p. 03. 
Escrita, práticas de leitura e circulação de manuais de devoção entre Portugal e Brasil nos séculos XVIII e XIX do Sul [Memorial Jesuíta da Universidade do Vale do Rio dos Sinos], quanto em Portugal, na Biblioteca Nacional, em Lisboa, e a Biblioteca Joanina, em Coimbra. Com o propósito de localizar evidências da circulação destas obras entre Portugal e Brasil, procedemos a um levantamento destes manuais devocionais junto a acervos brasileiros e portugueses, conforme pode ser conferido no Quadro 1. Alguns deles são traduções para o português de manuais escritos em espanhol, italiano, alemão ou latim ou, então, adaptações das versões originais, já que muitas delas sofriam mudanças, supressões ou acréscimos entre uma edição e outra ${ }^{24}$.

Observando o quadro abaixo, destacam-se algumas obras que compõem o acervo do Memorial Jesuíta, da Universidade do Vale do Rio dos Sinos (Unisinos) $^{25}$ : Pensai-o bem, ou, cuidados da alma, de Barthélemy Baudrand; Arte de Orar, de Diogo Monteiro; Combate Espiritual, de Lourenço Scupoli; Exercícios de perfeição e virtudes cristã, de Rodrigues Alonso; Guia de pecadores, de Luís de Granada; Retiro Espiritual, de Jean Crasset e, ainda, as obras completas do padre Manuel Bernardes. Já o acervo da Biblioteca Nacional do Rio de Janeiro, reúne literatura religiosa que pertencia aos integrantes da família real portuguesa, com destaque para a obra Desengano dos Pecadores, escrita pelo padre italiano Alexandre Perier. El devoto de la virgen Maria, do padre Paolo Segneri, Historia do predestinado peregrino, do jesuíta Alexandre de Gusmão e Cuidados da vida e descuidados da morte, do padre Boaventura Maciel Aranha. Todas estas obras podem ser também encontradas na Biblioteca Nacional de Portugal ou, então, na Biblioteca Joanina.

\section{Levantamento de Manuais de devoção presentes em arquivos brasileiros e portugueses}

\footnotetext{
${ }^{24}$ A historiadora Ana Cristina Araújo (1997, p. 147) já ressaltou que houve inúmeras traduções e adaptações de várias obras dessa literatura espiritual, enfatizando ainda que "o livro, o objeto correlato de individualização da mensagem religiosa, pela adesão, indiferença ou rejeição que provoca, funciona como barômetro da sensibilidade religiosa de um tempo".

${ }^{25}$ O Memorial Jesuíta da Unisinos reúne, há mais de dez anos, "acervos e coleções de livros, periódicos e documentos relativos à memória e à história de atuação dos jesuítas no sul do Brasil", totalizando "mais de 200 mil itens, entre os quais um expressivo número de obras raras, editadas entre os séculos XV e XIX". As obras mantidas neste acervo não se restringem a publicações específicas da Companhia de Jesus, mas obras religiosas em geral que serviam aos seus objetivos. As coleções foram reunidas, "a partir da década de 1840, pelos jesuítas em diversas bibliotecas, necessárias a suas atividades educacionais, pastorais e sociais". O setor de obras raras, onde localizamos os manuais de devoção é extremamente rico em potencialidade documental, sendo formado pela agregação das seguintes bibliotecas: Patrum, do Colégio Cristo Rei de São Leopoldo, do Colégio Anchieta de Porto Alegre, do Colégio Santo Inácio de Salvador do Sul, do Colégio Gonzaga de Pelotas, do Colégio Stella Maris de Rio Grande, além de doações de particulares. Ver mais em ARENDT, Isabel Cristina. A atuação do historiador junto a acervos universitários: caso do Memorial Jesuíta Unisinos, ANAIS ELETRÔNICOS XI ENCONTRO ESTADUAL DE HISTÓRIA: história, memória, patrimônio, FURG, Rio Grande/RS, p. 471-480, julho 2012, p. 472. Por disponibilizar o acesso às coleções de obras raras e especiais, 0 Memorial Jesuíta, em 2011, "foi agraciado pelo Ministério da Cultura com o prêmio Ordem do Mérito Cultural, a mais alta condecoração da cultura brasileira".
} 


\begin{tabular}{|c|c|c|c|c|}
\hline Nome da Obra & $\begin{array}{l}\text { MJU } \\
\text { (Memorial } \\
\text { Jesuíta } \\
\text { Unisinos) }\end{array}$ & $\begin{array}{|ll|}\text { BNRJ } & \\
\text { (Biblioteca } & \\
\text { Nacional } & \text { do } \\
\text { Rio } & \text { de } \\
\text { Janeiro) } & \\
\end{array}$ & $\begin{array}{l}\text { BNP } \\
\text { (Biblioteca } \\
\text { Nacional de } \\
\text { Portugal) }\end{array}$ & $\begin{array}{l}\text { BJ } \\
\text { (Biblioteca } \\
\text { Joanina) }\end{array}$ \\
\hline $\begin{array}{l}\text { PERIER, Alexandre. Desengano dos } \\
\text { pecadores. }\end{array}$ & & Edição 1724 & $\begin{array}{l}\text { Edição 1735, } \\
1765\end{array}$ & \\
\hline $\begin{array}{l}\text { BONETA, Joseph. Gritos das almas } \\
\text { no Purgatório. }\end{array}$ & Edição 1869 & & Edição 1715 & \begin{tabular}{|l|} 
Edição \\
1711 \\
\end{tabular} \\
\hline MONTEIRO, Diogo. Arte de orar. & Edição 1630 & & Edição 1630 & \begin{tabular}{|l} 
Edição \\
1630
\end{tabular} \\
\hline $\begin{array}{l}\text { SALES, S. Francisco. Introdução à } \\
\text { vida devota. }\end{array}$ & Edição 1986 & $\begin{array}{l}\text { Edições 1875, } \\
1948,1958\end{array}$ & $\begin{array}{ll}\text { Edições } & 1682, \\
1729, & 1784, \\
1829, & 1900, \\
1938, & 1961, \\
2010 & \\
\end{array}$ & \begin{tabular}{|l|} 
Edições \\
1729, \\
1784, \\
1836, \\
1961,2010 \\
\end{tabular} \\
\hline $\begin{array}{l}\text { SCUPOLI, Lourenço. Combate } \\
\text { Espiritual. }\end{array}$ & Ediçao 1864 & Edição 1761 & $\begin{array}{ll}\text { Edição } & 1666, \\
1667, & 1674, \\
1683, & 1698, \\
1707, & 1741, \\
1744, & 1756, \\
1761, & 1780 \\
1783, & 1800, \\
1864, & \\
\end{array}$ & $\begin{array}{l}\text { Edições } \\
1698, \\
1707, \\
1741,1780\end{array}$ \\
\hline $\begin{array}{l}\text { SEGNERI, Paolo. El devoto de la } \\
\text { virgen Maria. }\end{array}$ & & Edição 1723 & Edição 1710 & \begin{tabular}{|l|} 
Edições \\
1710, \\
1723,1756 \\
\end{tabular} \\
\hline $\begin{array}{l}\text { BEQUEMAN, Thomas. Combate } \\
\text { Espiritual }\end{array}$ & Edição 1864 & & Edição 1761 & $\begin{array}{l}\text { Edição } \\
1741\end{array}$ \\
\hline $\begin{array}{l}\text { ARBIOL, Antonio. Desenganos } \\
\text { misticos das almas }\end{array}$ & & Edição 1713 & & \begin{tabular}{|l|} 
Edição \\
1746
\end{tabular} \\
\hline $\begin{array}{l}\text { NIEREMBERG, Juan. Diferença entre } \\
\text { o temporal e o eterno. }\end{array}$ & Edição 1945 & $\begin{array}{l}\text { Edições 1643, } \\
1653\end{array}$ & Edição 1692 & \\
\hline $\begin{array}{l}\text { ALONSO, Rodrigues. Exercício de } \\
\text { perfeição e virtudes cristãs. }\end{array}$ & \begin{tabular}{|l} 
Edições 1886, \\
1954
\end{tabular} & $\begin{array}{l}\text { Edições 1612, } \\
1625\end{array}$ & Edição 17-7 & \\
\hline SEGNERI, Paolo. Mana del Alma. & \begin{tabular}{|l|} 
Edições 1853, \\
1867
\end{tabular} & & & \begin{tabular}{|l|} 
Edição \\
1724 \\
\end{tabular} \\
\hline $\begin{array}{l}\text { VILLACASTIN, Tomás. Manual de } \\
\text { Exercícios Espirituais para ter oração } \\
\text { mental em todo o discurso do ano. }\end{array}$ & Edição 1926 & & & \begin{tabular}{|l} 
Edição \\
1744
\end{tabular} \\
\hline $\begin{array}{l}\text { ARANHA, Boaventura Maciel. } \\
\text { Cuidados da vida e descuidados da } \\
\text { morte. }\end{array}$ & & Edição 1743 & & $\begin{array}{l}\text { Edição } \\
1761\end{array}$ \\
\hline $\begin{array}{l}\text { SARMENTO, Francisco. Flos } \\
\text { sanctorum ou santuário doutrinal }\end{array}$ & Edição 1859 & & $\begin{array}{l}\text { Edições 1794, } \\
1867\end{array}$ & \\
\hline $\begin{array}{l}\text { CRASSET, Jean. Retiro espiritual (...) } \\
\text { para aqueles que desejam segurar } \\
\text { uma boa morte. }\end{array}$ & Edição 1851 & & $\begin{array}{l}\text { Edições } 1764, \\
1784,1786, \\
1900\end{array}$ & \\
\hline $\begin{array}{l}\text { GRANADA, Luis de. Guia de } \\
\text { pecadores e exortação à virtude. }\end{array}$ & \begin{tabular}{|l|} 
Edições de \\
1794,1873
\end{tabular} & Edição 1873 & $\begin{array}{ll}\text { Edições } & 1594, \\
1730, & 1764,\end{array}$ & $\begin{array}{l}\text { Edições } \\
1556,1594\end{array}$ \\
\hline
\end{tabular}




\begin{tabular}{|c|c|c|c|c|}
\hline cas & 1 & . & $\begin{array}{l}\text { Brasll nos seculos } \\
1700, \quad 1772, \\
1780, \quad 1800, \\
1844\end{array}$ & \\
\hline $\begin{array}{l}\text { GUSMÃO, Alexandre de. Historia do } \\
\text { predestinado peregrino }\end{array}$ & & Edição 1728 & $\begin{array}{l}\text { Edições 1682, } \\
1685,1728\end{array}$ & $\begin{array}{l}\text { Edição } \\
1728\end{array}$ \\
\hline $\begin{array}{l}\text { SEGNERI, Paolo. Devoto da Virgem } \\
\text { maria (El devoto de la Virgen) }\end{array}$ & Edição 18?? & Edição 1723 & & $\begin{array}{l}\text { Edições } \\
1710 \\
1723 \\
1756\end{array}$ \\
\hline $\begin{array}{l}\text { CALATAYUD, Pedro de. Doutrinas } \\
\text { practicas que costuma explicar nas } \\
\text { suas missões o padre Pedro de } \\
\text { Calatayud. }\end{array}$ & $\begin{array}{l}\text { Edição } 1747 \\
(4 v .)\end{array}$ & Edição 1747 & Edição 1747 & $\begin{array}{l}\text { Edição } \\
1753\end{array}$ \\
\hline $\begin{array}{l}\text { VOZ de Jesus Cristo pela boca dos } \\
\text { párocos... }\end{array}$ & Edição 17?? & & $\begin{array}{l}\text { Edições 1815, } \\
1830\end{array}$ & \\
\hline $\begin{array}{l}\text { BAUDRAND, Barthélemy (1701- } \\
\text { 1787). Pensai-o bem, ou, cuidados } \\
\text { da alma }\end{array}$ & $\begin{array}{l}\text { Edições 1869, } \\
1888,\end{array}$ & & $\begin{array}{ll}\text { Edições } & 1888, \\
1895, & 1900, \\
1909, & 1912, \\
1940, & 1943, \\
1945, & 1948, \\
1951, & 1954, \\
1956, & 1961, \\
\end{array}$ & $\begin{array}{l}\text { Edições } \\
1869, \\
1961,\end{array}$ \\
\hline $\begin{array}{l}\text { MARTÍNEZ DE LA PARRA, Juan. Luz } \\
\text { de verdades cathólicas }\end{array}$ & Edição 1761 & \begin{tabular}{|l|} 
Edições 1737, \\
1761
\end{tabular} & 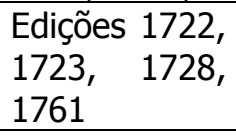 & $\begin{array}{l}\text { Ediç̃̃es } \\
1705, \\
1728,1737\end{array}$ \\
\hline $\begin{array}{l}\text { SACRAMENTO, Antonio do. Ventura } \\
\text { do homem predestinado }\end{array}$ & Edição 1938 & Edição 1763 & Edição 1763 & \\
\hline $\begin{array}{l}\text { SALAZAR, Francisco de. Affectos e } \\
\text { consideraçoens devotas }\end{array}$ & Edição 1750 & Edição 1743 & $\begin{array}{l}\text { Edições 1742, } \\
1842\end{array}$ & $\begin{array}{l}\text { Edições } \\
1731, \\
1742, \\
1743,1750\end{array}$ \\
\hline
\end{tabular}

Fonte: Elaboração dos autores a partir da consulta ao Catálogo dos referidos acervos.

\section{Evidências de circulação}

O levantamento acima, ainda que não evidencie o uso de tais livros, apresenta elementos que apontam para a inconteste circulação de manuais devocionais entre Portugal e Brasil ao longo do Setecentos e do Oitocentos. Neste artigo, nos debruçamos mais detidamente sobre três obras, priorizando sua estrutura, suas peculiaridades e as temáticas que abordavam. São elas: Gritos das almas no Purgatório, escrita pelo padre aragonês Joseph Boneta (1638-1741) e publicada, originalmente, em 1689; Desenganos dos Pecadores, escrita pelo padre jesuíta Alexandre Perier (1651-1736) e publicada em 1724; Mestre da Vida que ensina a viver e morrer santamente, escrita pelo padre português João Franco (datas de nascimento e morte desconhecidas) e publicada, inicialmente, em 1731. Estas três obras foram publicadas, traduzidas, editadas e reeditadas em Portugal, tendo circulado no Brasil ao longo dos séculos XVIII ou XIX. 
O manual Gritos das Almas teve aprovação pelo Santo Ofício em 1702 e a primeira edição traduzida para o português em 1711. Um indicativo de seu sucesso editorial são as várias edições que a obra teve em português, além das traduções para várias línguas, desde sua publicação ao final do século XVII ${ }^{26}$. Esse manual foi escrito pelo padre Joseph Boneta, natural de Zaragoza, doutor em Teologia que, além da obra aqui analisada, foi autor também de Vidas de Santos e veneráveis varões, Crisol do Crisol, Gritos do Inferno, Graça da Graça.

A edição de que nos valemos é a da segunda metade do século XIX, disponível no setor de obras raras do acervo do Memorial Jesuíta da Unisinos, e, curiosamente, ausente dos catálogos de algumas das principais bibliotecas portuguesas. Esta edição de Gritos das almas no Purgatório foi publicada pela Typographia do Jornal do Porto, na cidade do Porto, em 1869, portanto, 180 anos após a primeira. Trata-se de uma tradução para o português, realizada pelo padre Manoel de Coimbra, clérigo sacerdote do hábito de São Pedro, e oferecida pelo provedor e todos os irmãos da Irmandade das Almas (instituída na capela de São Pedro) ao Príncipe Dom João, de Portugal. No frontispício da obra encontramos a informação de que esta "nova edição [estava] conforme a de 1711 ", o que sugere que não tenham sido feitas alterações.

Em uma referência à recepção que a primeira edição da obra teve ao ser lançada em 1689, o próprio autor informaria no Prólogo da segunda, publicada em 1711, que "como na primeira impressão não romanceei estas palavras, houve a quem não soou bem este vocábulo Gritos, para ser articulado pela boca das almas", o que não impediu, contudo, que na aprovação do Santo Ofício de 1702, Grito das Almas tivesse sido classificada como "obra muito douta", "digníssima da luz e aceitação universal", por Francisco de Santa Maria.

Gritos das Almas do Purgatório é fruto, pode-se dizer, da prolongada crença no Purgatório, especialmente, nas almas do Purgatório, que ganhou amplitude após a realização do Concílio de Trento, período em que mereceu "grande apreço" o "sentimento devoto de expressão forte", capaz de influenciar e comover os fiéis ${ }^{27}$. 0 autor instruía o fiel a rezar pelas almas que buscavam a expiação de seus pecados no Purgatório, esse intermediário entre o Paraíso e o Inferno, lugar de purificação da variedade de culpas, de reclusão de almas pobres, sofredoras, necessitadas de sufrágios. Padre Boneta também 0 incentivava a agir como um "afetuoso solicitador dessa devoção". Uma alma do purgatório poderia "ser mais poderosa" do que o "maior santo do céu" no atendimento do fiel, como se podia constatar em Santa Catarina de Bolonha (1413-1463), que teria recorrido às "benditas almas" com muito sucesso.

${ }^{26}$ OLIVEIRA, Maria Gabriela Gomes. Horrores breves, horrores eternos. Uma reflexão sobre a obra Gritos do Inferno para despertar ao mundo do Padre Joseph Boneta, Revista Fac. Letras, Porto, p. 103-111, 1997, p. 112.

27 OLIVEIRA, Maria Gabriela Gomes de. Uma 'irmandade' volante do século XVIII: o folheto 'Lágrimas das almas', Instituto da Cultura Portuguesa, 1991, Disponível em http://ler.letras.up.pt/uploads/ficheiros/2657.pdf. Acessado em 22 nov. 2011. VOVELLE, Michel. As almas do purgatório, ou, O trabalho de luto. Trad. Aline Meyer e Roberto Cattani. São Paulo: Ed.Unesp, 2010. LE GOFF, Jacques. O Nascimento do Purgatório. Lisboa: Estampa, 1993. 
Escrita, práticas de leitura e circulação de manuais de devoção entre Portugal e Brasil nos séculos XVIII e XIX

A obra é dividida em "dois livros": o Livro Primeiro, intitulado Gritos das almas, com doze capítulos, e o Livro Segundo, intitulado Meios para aplacar estes gritos, com nove capítulos. No primeiro, padre Boneta apresenta a gravidade das penas no Purgatório e os sofrimentos das almas por parte de maridos, mulheres, pais, filhos, parentes e herdeiros, incentivando a devoção às almas. E no segundo, enumera e discursa sobre os socorros às almas, entre eles, a audição de missas, as esmolas e as orações. Estabeleceu, ainda, inúmeras prescrições de reordenamento de atitudes e sentimentos necessários para a garantia da salvação e do bom encaminhamento da alma no além. Constata-se que para produzir mudanças na conduta de seu potencial leitor, Boneta recorre a

uma técnica de ficção, não original, mas convincente, em que põe o mundo do Além a comunicar com o mundo terreno. Os condenados, da única maneira que lhes é possível, aos gritos forma que tanto indica a veemência do castigo como a urgência do aviso - alertam os pecadores dos perigos que os aguardam se não arrepiarem caminho e descrevem os suplícios a que estão sujeitos ${ }^{28}$.

No prólogo, o padre Boneta esclarece que Grito das Almas era o quinto livro "que me fizeram dar à estampa" e que atendia ao "benefício das benditas almas". Ao leitor, ele fazia a recomendação de que entendessem os "gritos" como se os mesmos partissem das próprias almas, assim, "quando lerdes os Gritos (...) os leias não como escritos por mim se não como articulados por elas". Acrescentava, ainda, que a leitura deveria ser acompanhada da imaginação do leitor, que deveria acreditar estar vendo e ouvindo um "defunto" familiar como pai, parente ou amigo.

Em relação ao manual Desengano dos Pecadores, publicado em Portugal em 1724, pelo padre italiano Alexandre Perier, "missionário da Província do Brasil", trazia na contrapaca a informação de que era "necessário a todo gênero de pessoas" e que seria "utilíssimo aos missionários e aos pregadores desenganados que só desejam a salvação das almas". Interessante notar que a obra não veio acompanhada da famosa referência "com todas as licenças necessárias", e sim, com a expressão "com licenças dos superiores". São três as "Aprovações" apresentadas depois da Introdução e antes do Sumário: do padre Michael Angelus Tamburinus; do Mestre Diogo Curado, da Congregação do Oratório de Lisboa; e do Reverendo Antonio de Santa Clara, na ocasião exvigário geral dos Reformados de Santo Agostinho.

O livro de Perier pode ser localizado tanto na Biblioteca Nacional do Rio de Janeiro (edição de 1724), quanto na Biblioteca Nacional de Portugal (edições de 1735 e 1765). Neste artigo, estamos nos valendo da edição de 1724, dedicada ao Cardeal Nuno da Cunha, inquisidor geral dos Reinos e Senhorios de Portugal.

Nas primeiras quarenta páginas do livro encontramos a dedicatória, seguida da introdução, das instruções "ao pio leitor", das aprovações escritas em latim, e, por último, do Sumário. Na "conversa" estabelecida com o leitor,

${ }^{28}$ OLIVEIRA, Maria Gabriela Gomes. Horrores breves, horrores eternos, Op. Cit., p. 104. 
Perier afirmava estar apresentando remédio seguro para a "vossa salvação" ao longo de suas quase 500 páginas, embora tenha se referido à obra como "pequeno volume".

A obra apresenta várias imagens ${ }^{29}$, as mesmas que seriam consideradas "ridículas estampas" pela Real Mesa Censória na década de 1770, levando à condenação oficial de sua publicação e divulgação ${ }^{30}$. O manual pretendia mostrar que "os bens e os males da vida futura excedem sem proporção e medida os bens e os males da vida presente", ${ }^{31}$ explorando visualmente os terríveis "tormentos do inferno", com inúmeras gravuras que, ao que tudo indica, teriam sido usadas em seu trabalho de conversão em Pernambuco do final do século XVII.

Considerando que a obra foi censurada cinquenta anos após sua primeira edição em 1724, ela, certamente, circulou e serviu de leitura religiosa a inúmeros fieis em Portugal e na América, pois teve, no mínimo, mais duas edições publicadas após a inicial, 1735 e 1765.

Ao todo, o manual apresenta catorze "discursos", que demarcam os capítulos do livro, indicando os devidos "tormentos" que seriam sofridos pela alma no inferno, acompanhados das gravuras cuja autoria não é identificada, mas que, segundo a historiadora Ana Cristina Araújo, seriam produções de Theodor de Bry (1528-1598). As imagens, possivelmente utilizadas para acentuar a dramaticidade do estado da alma pecadora no pós-morte, impunham ao leitor/observador um exercício de reflexão capaz de despertar o cristão para a vida cristã virtuosa e para os perigos da condenação na eternidade.

O último manual que destacamos como exemplo de obras publicadas ou editadas em Portugal e que chegaram ao Brasil é Mestre da Vida que ensina a viver e morrer santamente, do padre dominicano português João Franco. A obra, publicada inicialmente em 1731 obteve absoluto sucesso editorial no século XVIII, chegando a alcançar a marca de 16 mil exemplares ao longo de oito edições apenas até o ano de 1747. O objetivo do autor era o de levar a instrução quanto aos "mistérios da religião" católica, destacando "verdades" e encaminhamentos "à virtude e à perfeição" de tal modo que o fiel leitor alcançasse "vida e morte santa" e da mesma forma uma "eternidade feliz e

29 Estas imagens diziam respeito ao inferno, aos demônios e aos sofrimentos infringidos eternamente aos pecadores. Ver mais em FLECK; DILLMANN, 2013.

${ }^{30}$ A Revista de História da Biblioteca Nacional, na sua edição 94, de julho de 2013, na seção "Por dentro da Biblioteca" trouxe uma reportagem de uma página destacando algumas obras que sofreram censura, mas que "sobreviveram nas estantes da realeza", sendo uma delas, o Desengano dos pecadores. Sabe-se que esta obra, apesar de censurada pela monarquia portuguesa - a Biblioteca Nacional guarda os editais de censura de D. José I - estava entre os livros de D. Maria I, entre 1777 e 1816. JUSTEN, Janine. Os proibidões da rainha, Revista de História da Biblioteca Nacional, ano 8, n. 94, p. 89, julho, 2013. O que importa destacar é que, apesar de ter sido censurada, a própria família real guardava obras como esta em sua biblioteca particular. É possível que a obra, ao ter sido proibida na década de 1770 , já se encontrasse nos acervos privados de muitos indivíduos ou famílias, já que era editada e comercializada desde 1724.

${ }^{31}$ ARAÚJO, Op. Cit., p. 156 
Escrita, práticas de leitura e circulação de manuais de devoção entre Portugal e Brasil nos séculos XVIII e XIX gloriosa"132. João Franco foi um prolífero autor de literatura religiosa, dentre os quais destacamos seus Sermões, publicados em 10 volumes, além dos manuais Terceiro Instruído na Virtude, Mestre da Virtude e Vida portentosa da serva de Deus D. Thomázia de Jesus.

Na Biblioteca Nacional de Lisboa foi possível localizar, dentre as inúmeras edições de Mestre da vida, edições dos anos de 1744, 1746, 1758, 1799, $1821^{33}$, já no Memorial jesuíta da Unisinos, tivemos acesso a uma edição inédita de 1882. Diversos historiadores brasileiros já indicaram evidências concretas da circulação desta obra no Brasil setecentista. Se Laura de Melo e Souza $^{34}$ indicou que um exemplar do Mestre da Vida na Bahia Colonial era utilizado por padres em suas práticas de exorcismo, Maria Aparecida de Menezes Borrego ${ }^{35}$ verificou a circulação dessa obra em São Paulo do século XVIII, a partir de levantamentos em inventários pos-mortem de alguns comerciantes, enquanto Marília de Azambuja Ribeiro e Luísa Santos ${ }^{36}$ identificaram esse manual em inventário da livraria da Fazenda jesuíta Santa Cruz no Rio de Janeiro, datado de 1759.

O conteúdo de Mestre da vida está inteiramente de acordo com os principais pontos da soteriologia católica. Seu discurso moral e doutrinário está, plenamente, ajustado à filosofia católica, especialmente com a ideia de pecado inevitável, com o sentimento de culpa (mea culpa, mea máxima culpa), com a determinação de que fora da Igreja não havia salvação, com o entendimento do além (céu, purgatório, inferno), com a arte de morrer e com a necessidade de oração (rogai por nós) ${ }^{37}$. João Franco propunha ao leitor "exercícios devotos", considerados úteis para "regularmos a nossa vida", "socorros" com "unção sagrada", orações, meditações, cuidados com os doentes e outras instruções que eram tidas como necessárias para a garantia de vida e morte santa e, principalmente, de uma eternidade feliz.

Os textos religiosos, vale lembrar, possuíam inegáveis pontos de interseção e aproximação, constituindo "um universo aberto a realidades extratextuais (...) e que nele se projetam" e, portanto, "aberto[s] a outros textos que retoma[m], contradiz[em] ou transforma[m] ${ }^{\prime \prime 38}$. Considerando que muitos autores de manuais exerceram suas funções religiosas numa mesma época, é bastante provável que lessem uns aos outros ou que recorressem às mesmas publicações das obras dos doutores da Igreja, das quais extraíam passagens e instruções que, assim, se perpetuavam continuamente. Uma das

\footnotetext{
${ }^{32}$ FRANCO, 1882 [1731], p. v-vii. Apud. FLECK; DILLMANN, 2012, p. 84.

33 RODRIGUES; DILLMANN, 2013, p. 04.

${ }^{34}$ SOUZA, Laura de Mello e. O diabo e a terra de Santa Cruz: feitiçaria e religiosidade popular no Brasil Colonial. 2. ed. São Paulo: Companhia das Letras, 2009 [1986], p. 158.

35 BORREGO, Maria Aparecida de Menezes. Entre as fazendas da loja e os trastes da casa: os livros de agentes mercantis em São Paulo setecentista. In: ALGRANTI, Leila Mezan; MEGIANI, Ana Paula. O Império por escrito: formas de transmissão da cultura letrada no mundo ibérico (séc. XVI-XIX). São Paulo: Alameda, 2009, p. 229-255, p. 235.

36 RIBEIRO, Marília de Azambuja; SANTOS, Luísa. A livraria da Fazenda Santa Cruz. In: ENGEMANN, Carlos; AMANTINO, Marcia. Santa Cruz: de legado dos jesuítas a pérola da Coroa. Rio de Janeiro: Eduerj, 2013. p. 145-179.

${ }^{37}$ EIRE, Carlos. Uma breve história da eternidade. Tradução: Rogério Bettoni. São Paulo: Três Estrelas, 2013, p. 145.
}

${ }^{38}$ PIRES, Op. Cit., p. 11. 
características desses manuais foi a de reproduzirem - quase literalmente - os escritos de doutores da Igreja e de santos padres, o que, no entanto, não se configurava em plágio, na medida em que tal procedimento era tido como resultante do "espírito científico de investigação". O mais importante era a "finalidade prática" desses manuais tidos como "obras de utilidade", especialmente, religiosa e moral ${ }^{39}$.

Assim como muitos outros que circularam entre Portugal e a América portuguesa, as três obras aqui destacadas apresentavam pequeno formato, sendo, portanto, facilmente manuseáveis, o que favorecia a leitura e o transporte. Por estarem divididos em vários capítulos, tornavam-se textos bastante didáticos, favorecendo a compreensão das instruções por parte dos fieis leitores. É inegável que o formato e a estrutura das obras muito contribuíam para a difusão das orientações propostas pelos religiosos, assim como o carisma de seus autores e o interesse do público leitor. Grito das Almas e do Mestre da vida tiveram reedições por quase de dois séculos, exemplares que atravessaram o Atlântico e foram lidos por padres e fieis católicos. É sobre o sucesso editorial destes manuais que refletiremos na continuidade, em especial, sobre as práticas de leitura e seus efeitos sobre os fieis católicos em Portugal e na América portuguesa.

\section{Práticas e possibilidades de leitura}

Como bem observado por Roger Chartier, no âmbito da História Cultural, os objetos impressos são analisados na sua materialidade, no âmbito da circulação em larga escala e das possíveis e numerosas utilizações feitas do texto escrito ou editado pelas tipografias. ${ }^{40}$ Estudos sobre história da leitura, da impressão e da circulação de livros e ideias também consideram as mediações existentes entre livros e leitores, ou seja, sobre as práticas de leitura e as formas de apropriação das ideias contidas nos livros ${ }^{41}$.

Reconhece-se, contudo, o quão difícil é capturar as interpretações que foram feitas destes manuais tanto em Portugal, quanto América Portuguesa, e avaliar sua recepção e apropriação pelos fieis católicos nas duas margens do Atlântico. Se a republicação destes discursos não pode ser tida como termômetro plenamente confiável para avaliarmos a apropriação - devido à prática inventiva e própria do compartilhamento de ideias e leituras ${ }^{42}$ - não devemos minimizar a sensibilidade e o pensamento religioso que eles

\footnotetext{
39 SOUZA, Laura de Mello e. Inferno Atlântico. Demonologia e colonização, séculos XVI-XVIII. São Paulo: Companhia das Letras, 1993, p. 74.

${ }^{40}$ CHARTIER, Roger (org.). As utilizações do objeto impresso (séculos XV-XIX). Tradução Ida Boavida. Portugal: Difel, 1998, p. 21.

${ }^{41}$ Sobre uma crítica nesse sentido, ver VILLALTA, Op. Cit., 1998.

${ }^{42}$ CHARTIER, Op.Cit., 1998, p. 20.
} 

representavam, e que, em boa medida, era partilhado por muitos sujeitos ${ }^{43}$. Pensamento que se expressava nos discursos veiculados por estes manuais, cujo maior propósito era o de "influenciar os leitores e levá-los à prática da virtude ${ }^{\prime 44}$.

Refletindo, justamente, sobre esta dificuldade de mensurar a recepção e, consequentemente, a apropriação feita dessas orientações que visavam à virtude, a historiadora Dominique Julia analisa o texto da obra Buquê da missão, escrita pelo religioso Jean Leuduger, que incentivava até mesmo os iletrados a possuírem bons livros, pois "mesmo que não saibas ler, não deixes de ter bons livros, a fim de que outros façam sua leitura para vós" ${ }^{45}$, situação que observou em uma devota que, mesmo analfabeta, carregava um manual sempre consigo. Ao se indagar sobre se "o modelo espiritual dessa devota iletrada foi frequente?", Julia alerta para a impossibilidade desta avaliação, já que "Aqueles ou aquelas que viveram essa experiência não fizeram confidências a respeito" ${ }^{\prime 4}$.

O certo é que no período moderno, muitos se valiam da audição para instruir-se religiosa e moralmente, pois eram frequentes as leituras feitas em voz alta, como apontam os estudos de Roger Chartier para a França ${ }^{47}$. Também na Alemanha do Setecentos, os campesinos e as camadas inferiores citadinas tinham acesso aos livros de orações e aos "livrinhos populares religiosos" que se difundiam nas feiras através da leitura em voz alta ${ }^{48}$. Na América Portuguesa, certamente, a situação não se diferenciava e esses manuais de devoção devem ter tido suas orientações apropriadas pelos poucos fieis leitores e por uma maioria de ouvintes.

Tratando da publicação de romances na Europa da época moderna, entre o século XVI e o XVIII, Roger Chartier ${ }^{49}$ destacou que "o romance deve ser frequentado do mesmo modo que o texto sagrado o é", demonstrando, assim, o quanto era comum e importante para os grupos letrados o acesso à literatura espiritual. Chartier informa, ainda, que o público leitor de obras de devoção (instruções religiosas, vidas de santos, livros de orações) do século XVIII era "muito mais numeroso" do que o público de romances ou mesmo da literatura clássica humanista, sendo formado, em sua essência, por pessoas idosas, viúvos(as), e casados de todas as camadas sociais ${ }^{50}$.

\footnotetext{
${ }^{43}$ Maria Manuela Rodrigues analisou diversos casos de indivíduos/leitores portugueses que, em seus testamentos, enumeravam os livros que possuíam, ou seja, suas bibliotecas particulares. RODRIGUES, Maria Manuela. Notícias breves para a história dos leitores e da leitura na cidade do Porto (1657-1746), Via spiritus, n.4, p. 233-242, 1997.

44 PIRES, Maria Lucília Gonçalves. Para uma leitura intertextual de 'Exercícios Espirituais' do Padre Manuel Bernardes. Lisboa: Instituto Nacional de Investigação Científica, 1980, p. 114.

${ }^{45}$ JULIA, Op. Cit., 1999, p. 108

${ }^{46}$ Ibid.

${ }^{47}$ CHARTIER, Op. Cit., 1994, p. 98.

${ }^{48}$ WITTMANN, Reinhard. Existe uma revolução da leitura no final do século XVIII? In: CAVALLO, Guglielmo e CHARTIER, Roger (org.). História da leitura no mundo ocidental. Vol. 2. São Paulo: Ática, p. $135-164,1999$, p. 141 . O público leitor nas sociedades semi-alfabetizadas era composto pelas mulheres de famílias burguesas.

49 CHARTIER, Op. Cit., 2002a, p. 102-103.

${ }^{50}$ CHARTIER, Roger. Leituras e leitores "populares" da Renascença ao período clássico. In: CHARTIER, Roger; CAVALLO, Guglielmo. História da leitura no mundo ocidental. São Paulo: Ática, p. 117-134, 1999.
} 
Como já apontado por vários historiadores brasileiros ${ }^{51}$, os livros religiosos, mais do que um inegável objeto de consumo ${ }^{52}$, favoreceram a circulação de ideias e propiciaram a divulgação de mensagens cristãs com fundo doutrinal e moral. Escritos para serem consultados e (re)lidos seguidamente, esses livros eram alvo de "releituras incessantes", que deveriam "acompanha[r] os tormentos e o cotidiano" para que suas instruções "vive[ssem] na memória" dos fieis e, assim, se torna[ssem] um guia para a existência" ${ }^{153}$.

\section{Considerações finais}

Embora a historiografia dedicada à análise das práticas de escrita e de leitura, da circulação de livros e da apropriação de ideias não seja recente, a relação entre circulação da literatura religiosa na América e os significados dos seus discursos no contexto metropolitano e no colonial, não mereceu, ainda, a atenção merecida por parte da historiografia brasileira ${ }^{54}$. A relevância destes estudos está não apenas na análise dos discursos morais-doutrinários contidos nos manuais de devoção que se encontram tanto em bibliotecas portuguesas, quanto em brasileiras, mas, especialmente, como procuramos demonstrar, na identificação de sua vitalidade, observada na sua reprodução, mediante reedições de manuais, ao longo de dois séculos.

Neste artigo, tratamos da circulação de livros religiosos entre Portugal e a América portuguesa, nos séculos XVIII e XIX, através de evidências da

${ }^{51}$ Dentre os historiadores, destacamos Lúcia Maria Bastos Pereira das Neves, Tânia Bessone, Maria Beatriz Nizza da Silva, Leila Algranti e Luiz Carlos Villalta. Vale conferir a revisão historiográfica realizada por VILLALTA em A história do livro e da leitura no Brasil Colonial: balanço historiográfico e proposição de uma pesquisa sobre o Romance. Disponível em http://www.caminhosdoromance.iel.unicamp.br/estudos/ensaios/.

${ }^{52}$ Nesse sentido, para Portugal, ver RIBEIRO, Maria Manuela Tavares. Livros e leituras no século XIX, Revista de História das Ideias, vol. 20, p. 187-227, 1999.

${ }^{53}$ Estas maneiras de ler marcadas pelo sagrado foram qualificadas por Chartier como "leituras intensivas", uma vez que eram textos escutados, lidos, relidos, memorizados, recitados e transmitidos para outras gerações. CHARTIER, 2002a, p. 108.

54 É preciso, no entanto, destacar o livro O Diabo e a Terra de Santa Cruz e Inferno Atlântico, de Laura de Melo e Souza, que, publicado no início dos anos 1990, já anunciava essa circulação de obras religiosas e ideias entre a metrópole e a colônia, ainda que sob a perspectiva, fundamentalmente, mas não exclusiva, da demonologia. Posteriormente, na perspectiva de análise de devoção da Virgem Maria a partir de escritos religiosos, destacamos os trabalhos da historiadora Juliana Beatriz Almeida de Souza, como Virgem Imperial: Nossa Senhora e império marítimo português. Luso-Brazilian Review, v.45, n.1, p.30-52, 2008. Entre as pesquisas recentes estão a desenvolvida por William de Souza Martins, sob a perspectiva de gênero, Representações femininas na obra do padre Manuel Bernardes (1644-1710). Lócus, v. 17, n. 2, p. 35-55, 2011, e de Célia Maia Borges sobre a espiritualidade dos tempos modernos, As obras de Frei Luís de Granada e a espiritualidade de seu tempo: a leitura dos escritos granadinos nos séculos XVI e XVII na Península Ibérica, Estudios Humanísticos. História. N. 8, p. 135-149, 2009. 
Escrita, práticas de leitura e circulação de manuais de devoção entre Portugal e Brasil nos séculos XVIII e XIX vitalidade editorial de três manuais de devoção - Gritos das Almas, Desengano dos Pecadores e Mestre da vida -, procurando vinculá-la ao formato e suporte das obras, ao estilo narrativo, aos recursos imagéticos e, ainda, às temáticas abordadas.

$\mathrm{Na}$ primeira metade do século XVIII, o discurso moral-religioso mantinha-se muito presente na sociedade portuguesa, o que pode ser observado nas atividades livreiras e de leitura ainda muito pautadas pelas ideias cristãs de salvação das almas fundamentadas em filósofos antigos e doutores da Igreja. Para Alexandre Perier, por exemplo, era Santo Agostinho a grande fonte de inspiração que incitava os cristãos a deixarem sua liberdade para se encerrarem "entre quatro paredes", fazendo penitências e chorando seus pecados. Dessa forma, o autor procurava convencer o "caro leitor" a mudar de vida, a afastar-se dos gostos momentâneos e dos vícios. Caso contrário, o fiel/leitor, segundo Perier, deveria "fechar este livro", já estando "morto antecipadamente para o inferno".

Os discursos impressionistas e amedrontadores estavam presentes nestes manuais, cuja leitura deveria ser assídua e constante. Guardá-los, carregá-los ou tê-los à mão na cabeceira do leito eram comportamentos esperados de um leitor católico, que deveria memorizar os conselhos, exortações e instruções e realizar os exercícios propostos pelos autores, especialmente, de práticas devocionais como a oração. Somente dessa forma, compreendendo a dimensão devota daquela sociedade, somadas, é claro, ao significativo crescimento das atividades editoriais e à ampliação das possibilidades de leitura, podemos entender a relevante proliferação da literatura cristã entre a Europa e o Brasil nos séculos XVIII e XIX.

\section{Sobre os autores}

Eliane Cristina Deckmann Fleck é doutora em História pela Pontifícia Universidade Católica do Rio Grande do Sul (PUC-RS). Professora da Universidade do Vale do Rio dos Sinos (Unisinos-RS), bolsista de produtividade científica do CNPq, nível 2. E-mail: ecdfleck@terra.com.br.

Mauro Dillmann é doutor em História pela Universidade do Vale do Rio dos Sinos (Unisinos-RS). Professor Adjunto da Universidade Federal do Rio Grande (FURG). Email: maurodillmann@hotmail.com.

Artigo recebido em 03 de novembro de 2014. Aprovado em 09 de dezembro de 2014. 